Revista Complutense de Historia de América

ISSN: 1132-8312

http://dx.doi.org/10.5209/RCHA.61085

\title{
De aguadores ambulantes a empresas distribuidoras. Historia del agua para consumo en Valparaíso (1850-1917) ${ }^{1}$
}

\author{
Inmaculada Simón Ruiz², Raúl Sánchez Andaur ${ }^{3}$
}

Recibido: 2 de octubre de 2016 / Aceptado: 28 de abril de 2017

Resumen. El objetivo de este estudio es dar cuenta de cómo se abastecía de agua para consumo la población de una ciudad como Valparaíso en la segunda mitad del siglo XIX, tiempo en que, sabemos, comienza a transformarse en una urbe de tipo cosmopolita, con los naturales problemas derivados de la modernización. Reseñamos las instancias de acopio y distribución antes y después de la modernización realizando una sistematización de las distintas fases por las que pasó desde el modelo inicial clásico hasta el moderno sistema de abastecimiento en red; igualmente nos ocupamos de sistematizar en manos de quien estuvo el servicio y el control del mismo durante las diferentes etapas. Nuestras fuentes son la prensa y los documentos y actas de la Municipalidad de Valparaíso.

Palabras clave: Abastecimiento de agua; modernización; gestión del agua; Valparaíso; Chile; siglo XIX.

\section{[en] From Water Carriers to Distribution Companies. History of Drinking Water in Valparaiso (1850-1917)}

\begin{abstract}
The aim of this study is to investigate the water supply for general public consumption in the city of Valparaiso during the second half of the 19th century, the period when the city becomes cosmopolitan.

We review the instances of water collection and distribution, before and after their modernization through, the systematic study of the different phases implemented in Valparaiso, starting with the classic supply model and finishing with the modern one. Finally, the analysis also reveals the main figures in charge of water supply system in Valparaiso at the time of these models. Our sources are the press, as well as documents and proceedings of the Municipality of Valparaiso.
\end{abstract}

Keywords: Water Supply; Modernización; Wáter Management; Valparaiso; Chile; 19th Century.

Sumario. 1. Introducción. 2. El abastecimiento tradicional. 3. Búsqueda de soluciones en red: concurso público y empresa municipal. 4. El debate antimonopolio y la fiscalización del servicio. 5. Conclusiones. 6. Referencias bibliográficas.

1 Este trabajo es resultado del proyecto de investigación Fondecyt Regular 1140292/2014 “Transformaciones políticas y socio-ambientales derivadas del cambio en el paradigma higiénico sanitario. Modernización del sistema de aguas en Chile a finales del siglo XIX: los casos de Valparaíso y Talca”. Agradecemos a los evaluadores sus comentarios.

2 Instituto de Estudios Sociales y Humanísticos de la Universidad Autónoma de Chile (Chile)

E-mail: isimonr@uautonoma.cl

3 Instituto de Estudios Sociales y Humanísticos de la Universidad Autónoma de Chile (Chile)

E-mail: rsancheza@uautonoma.cl 
Cómo citar: Simón Ruiz, I.; Sánchez Andaur, R. (2018) De aguadores ambulantes a empresas distribuidoras. Historia del agua para consumo en Valparaíso (1850-1917), en Revista Complutense de Historia de América 44, 191-210.

\section{Introducción}

Durante la segunda mitad del siglo XIX se lleva a cabo en las principales ciudades europeas y americanas el proceso de modernización del sistema de abastecimiento de agua para consumo urbano, y su posterior evacuación, conocido como la conquista del agua ${ }^{4}$. La creación de un sistema de aguas en red que facilitara la distribución y el control de la calidad del agua así como la evacuación de las aguas servidas y de lluvia no se llevó a cabo sin conflictos puesto que una de las primeras cuestiones que hubo que solucionar fue la de sobre quién debía recaer el costo y el mantenimiento y la gestión de las grandes obras que implicaba.

La introducción del nuevo sistema de abastecimiento de agua y saneamiento fue un campo de experimentación para los funcionarios liberales, que con frecuencia optaron porque fueran los propios usuarios quienes pagaran las obras de construcción, en lugar de que fuesen los ciudadanos a través de los impuestos ${ }^{5}$. El principal problema era que los municipios decimonónicos, quienes hasta entonces habían sido los encargados de velar por el abastecimiento urbano, apenas si contaban con recursos para asumir las obras necesarias para poner en marcha obras de tal magnitud. Es en este contexto en el que aparecieron los empresarios que, a título privado, contrataron concesiones con los municipios a través de las cuales obtuvieron el derecho a la explotación de una fuente de agua por un tiempo determinado a cambio de realizar las obras necesarias para ponerlo en marcha y de una serie de condiciones entre las que, generalmente, se incluían el abastecimiento gratuito a dependencias municipales y de caridad, así como el establecimiento de pilones o fuentes para uso de la ciudadanía. No obstante, no siempre se hicieron las concesiones a privados, también hubo modalidades de financiación mixta entre municipios y compañías (sociedades constituidas con capital nacional o extranjero) y empresas netamente municipales.

$\mathrm{Al}$ respecto, hay una amplia bibliografía para los casos de Estados Unidos ${ }^{6}$, Francia $^{7}$, España $^{8}$, México ${ }^{9}$. No obstante, para el caso de Chile, no contamos apenas con publicaciones que den cuenta de ellas de manera sistemática. Si contamos con algunas aportaciones parciales como la de Luis Castro ${ }^{10}$, e investigaciones sobre Valparaíso ${ }^{11}$ y Talca ${ }^{12}$ o con obras generales sobre el empresariado chileno y extranjero, como las más recientes de Nazer ${ }^{13}$ y Ortega Martínez ${ }^{14}$, y con trabajos que se ocupan

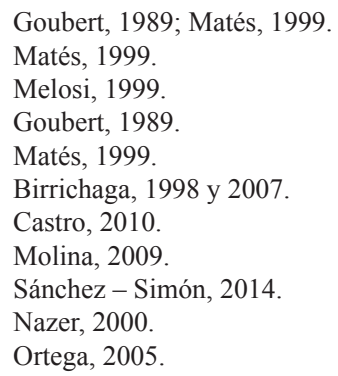


del abastecimiento desde una perspectiva social, como es el realizado por Ximena Urbina para los conventillos de Valparaíso ${ }^{15}$.

Tal vez una de las razones que expliquen la falta de trabajos sobre las empresas de agua sea la escasez y la dispersión de las fuentes. En Chile, las empresas de agua, en su mayoría de carácter privado, carecen de archivos históricos y, para el caso de Valparaíso, las escasas fuentes se encuentran diseminadas entre el archivo municipal de Valparaíso, el Archivo Histórico, el del Ministerio de Obras Públicas y el de la Administración; también contamos con alguna información de prensa, si bien al Biblioteca Nacional apenas si tiene periódicos porteños para el período que nos ocupa.

El trabajo que aquí presentamos es una primera aproximación al proceso de modernización del sistema de aguas en Valparaíso y a la problemática derivada del mismo. Iniciaremos con un recorrido por las formas tradicionales de abastecimiento para introducir, a continuación, el de la búsqueda de soluciones en red una vez que se instala en el discurso el nuevo paradigma higiénico sanitario en Chile. Enumeraremos las principales empresas que, a partir de la segunda mitad del XIX compitieron por el abastecimiento de la ciudad y de los barcos ubicados en la bahía, y daremos cuenta de la posterior creación de la Empresa Municipal en 1876, que supuso el inicio de la conflictividad entre defensores del servicio público y el privado, del debate en torno al monopolio y a la intervención del Estado al iniciarse el siglo XX, cuando se produce la fiscalización de la Empresa Municipal.

\section{El abastecimiento tradicional}

En la segunda mitad del siglo XIX, el puerto de Valparaíso, sufrió un proceso de crecimiento acelerado de población y el volumen de su comercio lo situaba entre uno de los principales puertos del Pacífico Sur. Como señala Cavieres, la ciudad no fue solo un foco de atracción para la población rural procedente del interior de país, sino también para extranjeros que se vincularon a actividades financieras, comerciales y marítimas. Si el crecimiento de la población chilena fue significativo a nivel país en esta etapa, lo fue con mucha mayor intensidad en Valparaíso, con un crecimiento anual de 3,9\% y el mayor número de población foránea del país ${ }^{16}$. Según datos estimativos, por la dificultad para realizar series ordenadas debido a la gran cantidad de población flotante, en 1854 la población era de 52.000 habitantes y para 1901 ascendía a $150.000^{17}$, lo que significa que se triplicó en menos de 50 años. Igualmente importante fue la desigual distribución, con una mayor concentración de viviendas en los cerros, debido a lo reducido de la franja disponible entre éstos y el mar, aunque con el tiempo, se fue ganando terreno al océano con las catastróficas consecuencias que esto ha tenido con el devenir de tsunamis, inundaciones e incendios. Otro problema recurrente ha sido -y continúa siendo- la falta de agua potable para abastecer a una población en continuo crecimiento.

Una lectura del plano de Valparaíso en el siglo XIX pone en evidencia la existencia de tres sectores claramente delimitados: los cerros, el plan y el puerto (Figura 1). Esta diferenciación no es meramente espacial puesto que cada uno de esos espacios tiene connotaciones específicas en cuanto al uso y aprovechamiento de las aguas y a la situación socio-económica de sus moradores.

\footnotetext{
Urbina Carrasco, 2012.

Cavieres, 2007: 131.

Flores, 2007: 146.
} 


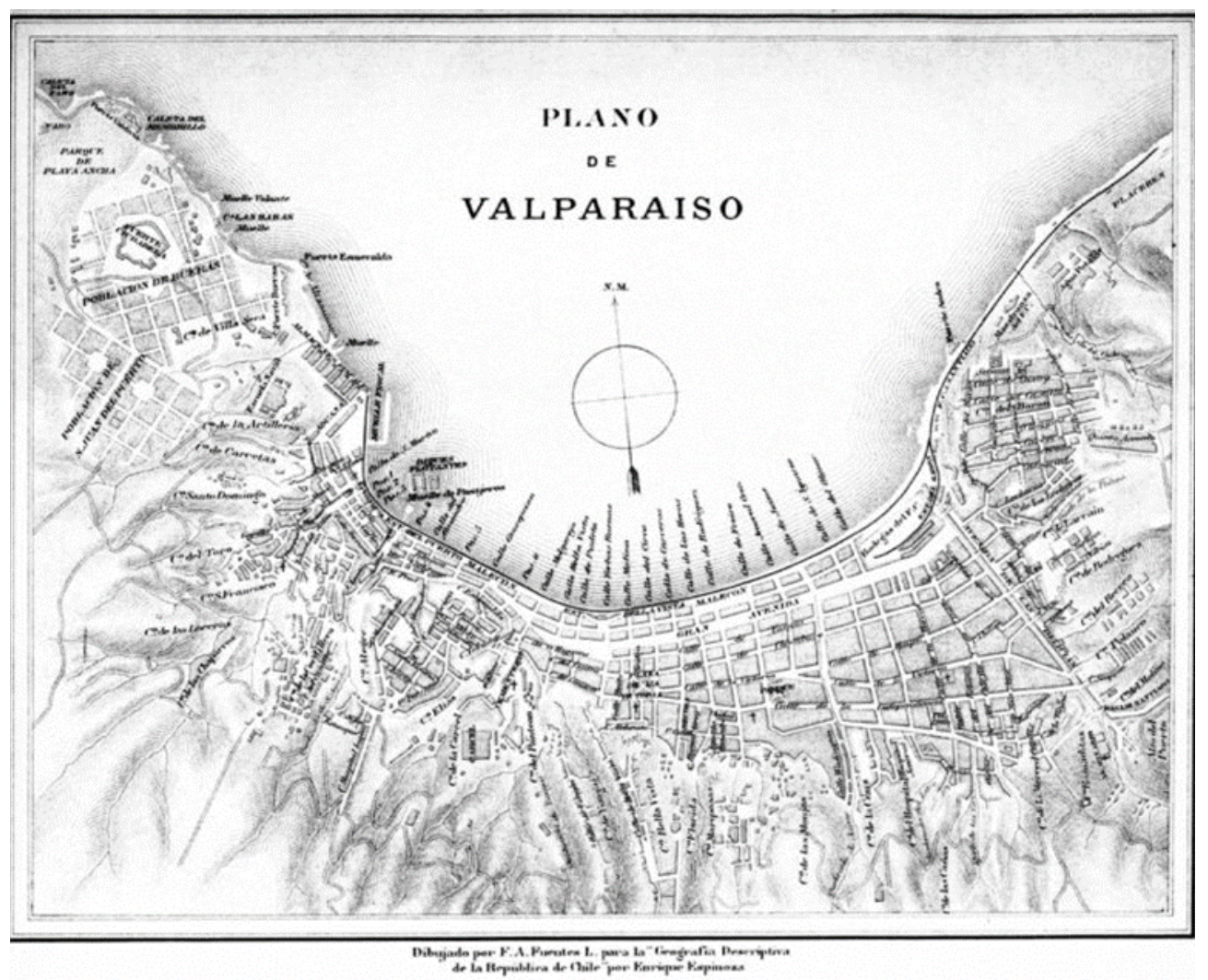

Figura 1. Plano de Valparaíso en $1879^{18}$

En los cerros se localizaban prioritariamente las personas procedentes del ámbito rural, muchas de las cuales llegaban para trabajar temporalmente en las labores del puerto, y terminaban asentándose definitivamente en condiciones bastante precarias en cuanto a seguridad e higiene. Las fuentes de abastecimiento de agua en estos cerros, hasta bien entrado el siglo XX, eran la gran cantidad quebradas existentes (del Barón, de Las Lavados, de Pocuro, de Las Cañas, del Litre, de Jaime, de las Jarcias, de Bellavista, de Yungay, de San Juan de Dios, de Elías, de San Agustín, de San Francisco, de la Cajilla, de Juan Gómez, de la pila del Carmen, etc.). Sus aguas eran conducidas a los domicilios por tomas, normalmente irregulares, por los tradicionales aguadores y por los propios moradores. En los cerros, sin embargo, se percibe una excepción, puesto que el Alegre y el de Concepción (en los que se localizó buena parte de la inmigración extranjera que llegó a la ciudad con capitales e iniciativa para emprender negocios) estaban habitados por personas con mayores recursos, quienes, a pesar de las dificultades para el acarreo del agua a esa altura, fueron abastecidos por la Compañía de Consumidores de Agua a partir de la década de 1870. Para la década de 1890 la población radicada en los cerros era de más de cien mil habitantes ${ }^{19}$, lo que suponía los 2/3 de la población total.

18 Fuente: www.memoriachilena.cl
19 Vela-Ruiz, 2014: 216. 
El resto de los ciudadanos se distribuía en el Plan, donde se radicaban, además, los grandes negocios, el centro comercial y las residencias de la burguesía. También se encontraba la municipalidad y todas sus dependencias así como los hospitales, escuelas, etc. En esta zona, el abastecimiento de agua era clave tanto para consumo como para higiene, ornato y control de incendios. Era en este sector en donde se localizaban las pilas de agua para abastecimiento público y de los aguadores que recorrían el Plan; fue también aquí donde se tendieron las primeras tuberías de agua. Otra forma de acceso frecuente era recurrir a los pozos que algunos habitantes tenían en sus hogares, sobre todo en la zona de El Almendral, donde las familias más solventes podían disponer de pozos particulares que se cavaban a unos 25-30 pies de profun$\operatorname{didad}^{20}$. No obstante, para la década de los cuarenta del siglo XIX, comenzaron a cuestionarse estas fuentes de abastecimiento puesto que no garantizaban calidad, dotación e higiene, y eran calificadas como malas, saladas y apenas suficientes para regar los pequeños huertos familiares ${ }^{21}$.

Por último, el puerto albergaba los almacenes y a los remolcadores y barcos cisterna que surtían de agua a los buques que diariamente recalaban y que suponían una importante fuente de negocio. Aquí, era fundamental el control de los incendios en los almacenes donde se guardaba el género que diariamente llegaba al puerto. Los buques cisterna se abastecían de agua obtenida de diversas maneras (desde pozos cercanos hasta barcos cisterna, pasando por el acarreo realizado por los aguadores), hasta que a mediados del siglo XIX, el propietario de la compañía de buques de vapor estableció la primera cañería desde la Quebrada de San Agustín hasta el puerto para el abastecimiento de los barcos localizados en la bahía, la que también distribuía el agua en algunas calles principales del plan y llegaba hasta la plaza de la Victoria.

Paralelamente a los sistemas tradicionales, desde mediados del siglo XIX fueron surgiendo nuevas iniciativas empresariales por parte de inversionistas particulares que comenzaron a ver en el agua un negocio a mayor escala, como recogemos de manera esquemática en el cuadro que presentamos a continuación.

Como se ve en la tabla 1, estos empresarios recibían la autorización del Ayuntamiento para hacer uso de las aguas a cambio de una serie de condiciones encaminadas a favorecer a toda la población. Este es el caso, por ejemplo, de la propuesta de Jacinto Vergara, quien en noviembre de 1858 solicitó al consistorio su autorización para construir en el barrio del estero de Jaime, en el Almendral, una pileta para surtir de agua al vecindario gratuitamente. Dicha pileta recibiría el agua de un estanque que el empresario pretendía construir en la quebrada para conservar el agua limpia antes de conducirla por tubería de fierro hasta la pila. A cambio solo exigiría, un centavo por carga a los aguadores que se abastecieran en ella ${ }^{22}$.

\footnotetext{
Urbina Burgos, 1999: 105. Su expresión en metros equivale entre 7 y 9.

Calderón y Schotfeldt, 2001: 182.

Acta Municipalidad de Valparaíso. 16-XI-1858. Archivo Histórico Nacional de Chile [Chile] (en adelante AHN), Municipalidad de Valparaíso (en adelante MV), vol. 33, f. 201.
} 
Tabla. 1. Propuestas de provisión de agua presentadas por empresarios privados ${ }^{23}$.

\begin{tabular}{|c|c|c|c|c|c|}
\hline Empresario & Financiación & Fecha & $\begin{array}{c}\text { Fuente } \\
\text { abastecimiento }\end{array}$ & $\begin{array}{c}\text { Aportación para } \\
\text { la ciudadanía }\end{array}$ & $\begin{array}{l}\text { Beneficio } \\
\text { empresa }\end{array}$ \\
\hline Jacinto Vergara & Privada & 1858 & $\begin{array}{l}\text { Quebrada Jaime } \\
\text { (actual Avenida } \\
\text { Francia) }^{24}\end{array}$ & \begin{tabular}{|l|} 
Construcción de \\
estanque y pileta. \\
Servicio gratuito \\
para Policia, \\
bomberos y \\
Hospital
\end{tabular} & $\begin{array}{l}\text { Monopolio de } 10 \\
\text { años } \\
\text { Autorización para } \\
\text { cobrar un centavo } \\
\text { por carga a los } \\
\text { aguadores }\end{array}$ \\
\hline W. Wheelwrigth & \begin{tabular}{|l} 
Privada, \\
Sociedad \\
Anónima \\
que contaba \\
con capital \\
estadounidense
\end{tabular} & 1849 & $\begin{array}{l}\text { Quebrada de San } \\
\text { Agustín (actual } \\
\text { Avenia José } \\
\text { Tomás Ramos) }\end{array}$ & $\begin{array}{l}\text { Servicio de } \\
\text { cañerías al puerto } \\
\text { y a la ciudad. } \\
\text { Servicio gratis a } \\
\text { bomberos }\end{array}$ & $\begin{array}{l}\text { Beneficio } \\
\text { derivado del } \\
\text { servicio y agua } \\
\text { para los barcos } \\
\text { de su Compañia } \\
\text { Naviera }\end{array}$ \\
\hline J. Waddington & $\begin{array}{l}\text { Privada, } \\
\text { Sociedad } \\
\text { Limitada } \\
\text { con sede en } \\
\text { Inglaterra }\end{array}$ & 1845 & Río Aconcagua & $\begin{array}{l}\text { Agua gratis para } \\
\text { pilas públicas } \\
\text { y lavanderías } \\
\text { populares }\end{array}$ & \begin{tabular}{|l} 
Beneficios \\
derivados del \\
servicio de \\
cañerías. \\
El agua llegó \\
hasta sus \\
haciendas \\
en Quillota y \\
Limache
\end{tabular} \\
\hline T. Bland Garland & \begin{tabular}{|l} 
Mixta: \\
Municipio/ \\
Sociedad \\
con sede en \\
Inglaterra
\end{tabular} & 1864 & $\begin{array}{l}\text { Quebrada de San } \\
\text { Juan de Dios, Rio } \\
\text { Quillota }\end{array}$ & $\begin{array}{l}\text { Agua para los } \\
\text { cerros de Playa } \\
\text { Ancha y servicio } \\
\text { gratuito para el } \\
\text { lazareto }\end{array}$ & $\begin{array}{l}\text { Beneficios } \\
\text { derivados del } \\
\text { servicio a los } \\
\text { cerros }\end{array}$ \\
\hline
\end{tabular}

Pedía, también, el beneficio exclusivo por 10 años y transcurrido ese período se comprometía a entregar las obras a la municipalidad, obligándose, además, a dar uso gratuito del agua al hospital de caridad, al cuartel de policía y al cuerpo de bomberos para sus operaciones. La inversión del empresario no era menor y no tenemos datos suficientes todavía para afirmar si pretendía resarcirse únicamente a partir del cobro a los aguadores o si tenía, además, algún interés especial por tener acceso al agua y a la construcción del estanque, pero sí podemos presentar dos casos de iniciativas privadas que le precedieron y encerraban otros tantos intereses que iban más allá de la dotación de agua a la ciudad. Se trata de los ciudadanos extranjeros William Wheelwrigth y Josué Waddington, quienes a mediados del XIX llevaron a cabo importantes obras de aprovisionamiento en Valparaíso.

En 1849 aparece en escena el Establecimiento Hidráulico y de Provisión de Agua $^{25}$ de William Wheelwright, quien proponía, a nombre de una compañía anónima de la que se presentaba como accionista, la celebración de un contrato para poner en planta inmediatamente un sistema hidráulico con el objeto de proveer de agua pura y potable a la población terrestre y marítima del puerto ${ }^{26}$.

23 Fuente: Elaboración propia.

24 Con el tiempo, el proceso de "conquista del agua" en Valparaíso supuso el soterramiento de todas las quebradas y su conversión en avenidas.

25 Documentos Municipalidad de Valparaíso. Valparaíso, 19-XI-1849. AHN, MV, vol. 68, f. 61.

26 Documentos Municipalidad de Valparaíso. Valparaíso, 19-XI-1840. AHN, MV, vol. 17, f. 141v. La provisión de barcos en el muelle se hacía por medio de un canal que se sacaba del depósito de San Agustín. 
Según un informe de 1875, la obra se llevó a cabo y sus instalaciones quedaron situadas en la quebrada de San Agustín, las que por sus características técnicas era capaz de contener 300.000 galones, además de otras menores que, en conjunto, aportaban otros $10.000^{27}$. En diciembre de 1849 se acordó fijar contrato por veinticinco años, que se prolongaría si la Municipalidad no aplicaba el derecho de compra, lo que evidencia que la Municipalidad veía el financiamiento y gestión privada como una cuestión provisional. En abril de 1850 se precisaba la amplia zona de alcance del servicio, que iría desde el lado occidental de la calle del circo hasta el camino que subía a Playa Ancha, comprendiendo la del área costado occidental, la plaza de la Victoria, la calle San Juan de Dios, la del teatro, la de Cochrane, las de la aduana, de la planchada y del Arenal ${ }^{28}$.

Llama la atención que su propuesta fue aceptada en primera instancia atendiendo a las ventajas que se iban a reportar, "principalmente con el recurso seguro, pronto y eficaz que por medio de ella se va a adquirir para contener los efectos del fuego en los incendios que sobrevengan en los hogares que cubrirá el establecimiento hidráulico" 29 . Esta referencia nos permite sostener que aún no se perciben de manera generalizada los beneficios del sistema en red de abastecimiento de aguas o su necesidad como medida higiénica y de salud pública sino que es necesario argumentar algo más, siendo la amenaza de los incendios y sus consecuencias económicas lo que estimula la contratación de la empresa por parte del Ayuntamiento para poder contar con acceso rápido y eficaz al agua.

No obstante, tan sólo una década después, en 1860, ya se percibe un interés por aumentar la dotación de agua; es entonces cuando el gobierno local decide entrar en acción. La Comisión de Policía y Obras de la Municipalidad, apelando a que las aguas de quebradas y vertientes pertenecían a la ciudad, planteó la conveniencia de extender el servicio a todo el Almendral por cuenta propia. La Comisión asumía que reuniendo estas aguas en estanques construidos a propósito, y economizadas las que se perdían en riego y descuido, podrían abastecer al doble de la población en todas sus necesidades. Haciendo el negocio en grande escala, la proyectada empresa municipal podría poner el agua a un precio tan módico que estuviera al alcance de los consumidores pobres ${ }^{30}$.

Frente a la amenaza de competencia por parte del Municipio, el empresario reaccionó comprometiéndose a la ampliación de la red y, así lo hizo, según consta en un informe emitido a inicios de la década de 1870 en el que indicaba que el servicio se había ampliado, cubriendo "la parte de Valparaíso conocida generalmente con el nombre de Puerto, i en la que están situados casi todos los edificios públicos, estensos almacenes particulares, hoteles i moradas i cuanto encierra de más valioso la ciudad"31.

Así, vemos cómo entre 1849 y 1870 las expectativas de dotación de agua a la ciudad variaron considerablemente. Se sigue viendo como prioritario el acceso al agua para proteger de los incendios a los edificios "más valiosos" pero la propuesta de intervención por parte de la comisión de policía y Obras Públicas de la municipalidad y del Municipio de hacer un uso racional para dar agua a mayor escala y a menor

\footnotetext{
Mannheim, 1876, s/f.

Documentos Municipalidad de Valparaíso. Valparaíso, 29-IV-1850. AHN, MV, vol. 33, s/f.

Documentos Municipalidad de Valparaíso. Valparaíso, 19-XI-1849. AHN, MV, vol. 17, f. 145v.

Documentos Municipalidad de Valparaíso. Valparaíso, 12-VI-1860. AHN, MV, vol. 33, s/f.

Mannheim, 1876, s/f.
} 
precio está señalando ya la entrada de una lógica mercantil centrada en el negocio del agua en sí y también de una preocupación por que los sectores más pobres de la ciudad pudieran tener acceso ${ }^{32}$.

No obstante, y volviendo a lo que señalábamos con anterioridad, consideramos que la iniciativa de Wheelwrigth a finales de la década de 1840 no vino dada por el interés en abastecer a la ciudad sino a los barcos que recalaban en la bahía, ya que era el propietario de la Pacific Stream Navigation Company, la cual inició su gestión con dos navíos y para 1875 contaba ya con 50 vapores $^{33}$. El empresario, tendiendo una cañería hasta el puerto, lograba aprovisionar de manera gratuita a sus barcos puesto que el acceso al agua había sido autorizado por el Municipio y el costo de las obras era cubierto por aquellos usuarios que se engancharon a la tubería para obtener el servicio. Así mismo, la cobertura de agua hasta el puerto facilitaba el acceso a los bomberos para hacer frente a los incendios que, con frecuencia, se desataban también en los almacenes ubicados en el puerto.

Con un interés también bastante particular, y no estrictamente centrado en el negocio del abastecimiento en sí, encontramos a Josué Waddington, quien en 1845 había iniciado la construcción de un canal que debería acarrear agua desde el Rio Aconcagua hasta Valparaíso según contrato con la municipalidad. Diez años después, el canal, denominado popularmente como la Guarintona (en atención a su propietario, conocido como Don Guarinto) ${ }^{34}$ sólo había sido concluido en su primer tramo, el cual recorría 70 millas hasta llegar a Quillota y Limache, justamente donde Waddington tenía dos haciendas: La Trinidad y San Isidro. En 1855 insistía con su propuesta para surtir de agua a la ciudad y señalaba que estaba avalado por The Valparaíso Water Work Company Limited, con sede en Londres y un capital ascendente 231.492 libras esterlinas. Con esas credenciales se comprometía a dotar gratuitamente de 100.000 galones de agua diarios a las pilas de uso público, lavanderías públicas para gente indigente y demás establecimientos. Para ello requería el auxilio de la policía "para que mediante su activa vigilancia pueda precavérsele de los daños y abusos que hubieren de entorpecer el buen régimen de la empresa" 35 .

El proyecto consistía en continuar el canal desde Quillota, para lo cual se le otorgaron seis años de plazo, con una vigencia contractual de treinta y tres años. De acuerdo a las fuentes, este tramo final del proyecto presentó diversas vicisitudes, ya que en 1860 se vuelve a ampliar el plazo, con la opinión en contrario de la comisión de Policía y Obras Públicas, debido a la vigencia del contrato con Wheelwright, con quien Waddington estuvo en conflicto durante todos esos años. En 1870 todavía no concluían las obras, quedando anulado definitivamente el proyecto para llevar el agua desde Quillota a Valparaíso.

Una de las cosas que revela el enfrentamiento entre ambos empresarios es el interés creciente por el negocio en sí y la tendencia a querer establecer un monopolio. A

32 La difusión del paradigma higiénico sanitario y, más adelante, los hallazgos en bacteriología y microbiología transformaron los estándares de calidad y la cuestión del agua urbana devino en un problema de salud pública. Si con anterioridad, la población tomaba el agua libremente de pozos y de acequias que corrían por las calles, la subida en los estándares de calidad y el, consecuente soterramiento de antiguos cauces para evitar el consumo de aguas contaminadas dejó a muchas personas sin acceso al agua y, por tanto, susceptibles de convertirse en clientes de las empresas de agua, fueran estas privadas o públicas.

33 The Pacific Steam Navigation, 1930: 44.

34 Vicuña Mackenna, 1877: 25.

35 Documentos Municipalidad de Valparaíso. Valparaíso, 07-II-1855. AHN, MV, vol. 33, f. 139. 
partir de entonces, siguiendo la estela de Waddington y de Wheelwrigth, fueron surgiendo otras iniciativas de empresarios y sociedades, como la de Jacinto Vergara ya mencionada, que propusieron al municipio sus servicios como proveedoras de agua. Entre ellas, destaca por la forma de financiación propuesta y por el modelo de acopio y conducción de agua sugerido, la realizada por la Compañía de Agua Potable de Valparaíso, de Tomas Bland Garland, quien, a partir de una propuesta de financiación mixta con el Municipio presentó proyecto, en 1864, para surtir de agua a la ciudad, trayéndola desde Viña del Mar, a razón de 1.500.000 galones diarios, repartiéndolos por medio de cañerías. La obra se estimaba en 550.000 pesos y para llevarla a cabo solicitaba un aporte municipal de 100.000 pesos. Se comprometía a llevar el servicio hasta los cerros de Playa Ancha y entregar agua gratis al lazareto. Aunque el aporte municipal fue rechazado por incompatible ${ }^{36}$, la compañía fue autorizada para iniciar una serie de trabajos de captación, descubriendo vertientes en la quebrada San Juan de Dios y en sus alrededores, obteniendo, así, diez manantiales de agua cristalina corriente, la que se almacenaba en un estanque desde el cual se distribuía por cañerías ${ }^{37}$. Dos años más tarde, daban cuenta de que sus ingenieros podían construir represas para recoger aguas de lluvia y de manantiales, y se proponía conducirlas por acueductos subterráneos a la ciudad, tal como se hacía en "todas las ciudades de Europa, Estados Unidos, Australia y la India" 38 .

A pesar de lo ambicioso de la propuesta y de haber contado con carta blanca para iniciar las prospecciones, la negativa de la Municipalidad a participar financieramente llevó a la casa matriz, ubicada en Inglaterra, a continuar con el proyecto.

Concluye, así, lo que consideramos una primera etapa en el proceso de abastecimiento de agua en red para la ciudad de Valparaíso. En tres de las propuestas presentadas se vio el predominio del capital extranjero, si bien en el último se contempla ya un tipo de financiación mixta. Por otra parte, en el caso de Wheelwrigth y Wadington se percibe que la inversión inicial de los empresarios está justificada por las necesidades de sus negocios particulares: la navegación a vapor y las haciendas, antes que por el negocio de suministro en sí dado el alto costo de instalación y la escasa cobertura que pretendían dar en un principio.

\section{Búsqueda de soluciones en red: concurso público y empresa municipal}

En la década de 1870 asistimos a un cambio muy visible en la estrategia por parte del Municipio. A pesar de los esfuerzos y propuestas por aumentar la calidad y la cobertura, el abastecimiento se mantenía precario e inestable, por lo que el municipio se vio obligado a tomar una serie de medidas conducentes a mejorar la situación. Entre ellas, estuvo la autorización para la apertura de pozos en puntos pertenecientes a la municipalidad o al fisco. A pesar de las recomendaciones que se venían dando desde la década de los 40 y que advertían de la insalubridad de las aguas de pozos, en 1873 se colocaron bombas "a fin de que la clase menesterosa se provea de agua gratuitamente para su uso doméstico, y los aguadores, abonando un centavo por cada carga, producto destinado a la conservación de esos pozos y en pago de individuos

\footnotetext{
Documentos Municipalidad de Valparaíso. Valparaíso, 03-II-1864. AHN, MV, vol. 33, s/f.

Vela-Ruiz, 2014: 216.

Documentos Municipalidad de Valparaíso. Valparaíso, 08-V-1872. AHN, MV, vol. 33., s/f.
} 
encargados de cuidarlos" ${ }^{39}$. En esta misma oportunidad se perciben nuevos pasos para la constitución de una empresa con carácter municipal ya que se acuerda "dedicar la cantidad de mil pesos para atender a los gastos que haya hecho y a los que hará en adelante el injeniero encargado de hacer los estudios para surtir de agua potable a la ciudad" 40 .

Un año antes, en 1872, el intendente Francisco Echaurren había abierto un concurso público y fijó las bases a que debían ajustarse los proponentes de la provisión de agua. A esta convocatoria se presentaron varias empresas, siendo declarada viable en un principio solo la propuesta de la Compañía de Consumidores de Agua, aun cuando la comisión encargada de la selección la terminó desechando, finalmente, el 15 de junio de 1874, aduciendo que el producto ofrecido era deficiente y de mala calidad $^{41} \mathrm{y}$ argumentando que:

\begin{abstract}
Valparaíso [...] quedara todavía por algún tiempo sin uno de sus servicios más indispensables. Pero nunca nos cansaremos de repetirlo: la situación actual es mala, casi insostenible, sin embargo mucho peor sería aquella en que quedaríamos colocados concediendo un monopolio de 30 años a una empresa que nos ofrece agua que no conocemos i que no puede asegurarla ni en la cantidad ni en la fijeza que requieren las necesidades de la población ${ }^{42}$.
\end{abstract}

La compañía de Consumidores había surgido a partir de la adquisición en 1871 de las instalaciones de la Compañía a William Wheelrigth junto con las que surtían al Cerro Alegre y las vertientes de Quebrada Verde, agua de la que proveían gratis a los aguadores en conformidad al convenio celebrado con la Ilustre Municipalidad en 9 de diciembre de 1873 . El enorme crecimiento de esta empresa ${ }^{43}$, además de la solicitud en la propuesta de unas condiciones de exclusividad, preocuparon al Municipio, el cual protagonizó un debate que ocupó los principales periódicos porteños en torno al servicio de aguas. El tema central del debate fue el riesgo a que el abastecimiento urbano se transformara en un monopolio, fuera esté privado o público. Los temores del Municipio no parecían infundados. Con un proyecto más ambicioso en cuanto a dotación de agua a la ciudad se refiere, la compañía de Consumidores de Agua, here-

39 Documentos Intendencia de Valparaíso (en adelante IV). Valparaíso, 08-II-1872. AHN, vol. 277, s/f.

40 Documentos Intendencia de Valparaíso. Valparaíso, 11-VI-1873. AHN, IV, vol. 277, s/f.

$41 \quad$ Díaz, 1888: 116.

42 Ibídem. Las otras propuestas rechazadas en aquella ocasión fueron: la de Martín Drouilly y Juan Stepan i Cía., y la presentada por Santa María, Vergara y otros en nombre de la Compañía de Comerciantes. Los ingenieros Drouilly y Stephan, con apoyo de Augusto Gubler proponían tomar el agua del canal de las Mercedes que estaba entonces en construcción y que supuestamente llevaría hasta Valparaíso las aguas del Mapocho. Estas aguas llegarían, según la propuesta hasta el Cerro Barón, después de surtir a Playa Ancha. La propuesta fue rechazada por el intendente con bastante acierto pues el proyectado canal, cuya construcción se puso en marcha a partir de la constitución del Canal de Las Mercedes, en 1854, no concluyeron hasta 1880 y el agua nunca llegó a Valparaíso, pues se detuvo en Curacaví; cfr. Documentos Municipalidad de Valparaíso. Valparaíso, 4-V-1874. AHN, MV, vol. 33, ff. 674 y ss. Por su parte, la Compañía de Comerciantes, La Compañía de Comerciantes, presidida por Jacinto Chacón, registrada en 1870 en la Bolsa, con capital de 330.000 pesos y que ofrecía entregar servicio por treinta años, a partir de un sistema novedoso de acopio de aguas de lluvia en represas que se ubicaría en Peñuelas, fue rechazada también a pesar de que comprometía dotación de agua para bomberos y 25 pilones o fuentes para uso público gratuito distribuidas por toda la ciudad. El proyecto fue retomado, más adelante, por parte de la empresa municipal de aguas.

43 Ortega, 2005: 151. Se establece en 1872, con un capital de 10.618 libras esterlinas. 
dera de la William Wheelwrigth, declaraba en el momento de su constitución que su objetivo era proveer a esta población del agua de manantial, en cantidad suficiente para todas sus necesidades y al más bajo costo ${ }^{44}$. Su radio de acción era similar al propuesto en los últimos años por Wheelwrigth, si bien se amplió en altura cuando adquirieron el acueducto del Cerro Alegre, con un estanque que tenía capacidad para almacenar 400.000 galones, para la provisión por cañería de los poblados barrios del Cerro Alegre y Cerro La Concepción ${ }^{45}$; disponían, además, de 200.000 metros cúbicos almacenados en la laguna de La Placilla, que tenía una capacidad de 800.000 metros cúbicos. Su propuesta de distribución consideraba abastecer también los cerros Alegre y Concepción, y la habilitación de pilones para venderla a los aguadores al precio de 20 centavos $^{46}$.

Por todo ello, la amplitud del alcance de la Compañía de Consumidores de Agua se había venido viendo en el municipio más que como una respuesta a la necesidad de abastecer de agua a la ciudad, como una posible amenaza de monopolio. Esa fue la razón de que su propuesta al llamado de Echaurren fuera desestimada, o al menos una de las razones, y esa fue también la razón por la cual el Municipio decidió dar mayor impulso a su propio proyecto de creación de una empresa municipal.

Al calor del debate por el monopolio al que hacíamos referencia con anterioridad, en 1876 el intendente Eulogio Altamirano, atendiendo a los cambios que había experimentado la ciudad y las expectativas de sus habitantes, opinaba que el servicio de agua potable debía ser un aporte público, argumentando que:

Una ciudad sin agua se hace más y más peligrosa para la vida en la medida que crece, a medida que aumenta la población. Por eso, lo que hace veinte años era una obra de previsión, ha llegado a ser en este momento una condición de salud y el reclamo incesante de todos los hombres amantes del progreso local y de su propio bienestar ${ }^{47}$.

Estudiadas las posibilidades, en enero de 1877 se discutieron las bases para la constitución de la Empresa Municipal de Agua Potable, aceptándose el proyecto de los ingenieros Lyon y Kammerer de traer agua desde El Salto (en Viña del Mar), río San Francisco del Monte, río Aconcagua, estero Marga-Marga, laguna del Inca o lago Peñuelas. Para su financiamiento se acordó solicitar un préstamo por 300.000 pesos, amortizable en 15 años y garantizado por los bienes de la empresa, iniciativa que no contó con el interés de los grandes inversionistas, por lo que se decidió -en una acción política inédita- emitir bonos por 200, 500 y 1000 pesos, a 10\% de interés, y una amortización acumulativa de $4 \%$ anual que se verificaría por sorteo al fin de cada semestre ${ }^{48}$.

Esta actitud estratégica se podría interpretar como una manera de demostrar a los grandes capitales que no eran imprescindibles. Por esta vía, la Municipalidad se abría a lograr el financiamiento por medio de la adhesión ciudadana al proyecto, ya que el 23 de marzo de 1877 se convocó a una reunión publica en la Bolsa de

44 Documentos Municipalidad de Valparaíso. Valparaíso, 15-XII-1869. AHN, MV, vol. 33, s/f.

45 Ibídem.

46 Documentos Municipalidad de Valparaíso. Valparaíso, 4-V-1874. AHN, MV, vol. 33, f. 415.

47 El Mercurio de Valparaíso, ${ }^{\circ}$ 14980, 23-III-1877, 4.

48 Documentos Municipalidad de Valparaíso. Valparaíso, 7-I-1887. AHN, MV, vol. 47, ff. 1-42. 
Valparaíso, invitando al público en general a participar como inversores y haciendo alusión a que evitar el monopolio privado sería toda una lección de patriotismo. En la convocatoria, el intendente Altamirano señalaba:

Creemos que hai una grande obra de patriotismo que realizar, predicando el ahorro y enseñando al pequeño industrial, a la viuda, al pobre, en fin, como pueda colocar con más seguridad y con mejor provecho sus pequeños intereses. Hacemos un llamamiento a su buena voluntad, firmemente persuadidos de que si realizamos nuestro propósito en la forma que dejamos indicado, no será la provisión de agua el mayor de los bienes alcanzados. Nos dirigimos en esta ocasión mui principalmente a aquellos de nuestros conciudadanos que forman en las filas de los desheredados de la fortuna a la vez que en las filas de la virtud y el trabajo ${ }^{49}$.

A pesar de que la provisión de equipamiento, contratada con la empresa Williamson Balfour, demoro más de lo presupuestado, con el consecuente incremento de los costos derivado de la acumulación de intereses de la deuda por la demora ${ }^{50}$, las obras se llevaron a cabo y, en mayo de 1881, la empresa municipal avisaba a su clientela de la ampliación del servicio al Almendral a muy bajo coste ${ }^{51}$, de la instalación de medidores y de abastecimiento a las lanchas cisterna ${ }^{52}$. El éxito de la empresa se expresaba así, en 1886, cuando el Concejo Municipal anunciaba que:

no solo llevó a cabo una importante obra en beneficio de la ciudad surtiendo con agua potable abundante i de la mejor clase la parte plana de la población, sino que realizó un buen negocio pues hasta ahora esa empresa no le cuesta un centavo de desembolso ni le costará en adelante, hasta el completo pago de la deuda ${ }^{53}$.

Todo ello la estimuló a potenciar el crecimiento de la empresa y la monopolización del servicio en manos del municipio proveyendo también a la parte alta de la ciudad $^{54}$. A partir de entonces se observa un alto nivel de inversión para aumentar la provisión, consistente en la compra de terrenos, prospección de nuevos pozos en la zona del Salto y reparación de la maquinaria utilizada, asuntos financiados sin recurrir a gastos municipales extraordinarios, y en asegurar la calidad del producto, a pesar de que las obras del Salto en 1887- un nuevo pozo y la correspondiente estación de bombas- costaron alrededor de $80.000^{55}$.

Oferta y demanda fueron aumentando de manera progresiva en paralelo al proceso de modernización del país y de adaptación a las nuevas directrices dictadas por los códigos sanitarios nacionales e internacionales que establecían normas de conducta en materia de salubridad e higiene. A partir del aumento de la demanda y de los cambios en las expectativas de la calidad de las aguas, éstas comenzaron a percibirse

\footnotetext{
El Mercurio de Valparaíso, $\mathrm{n}^{\circ}$ 14980, 23-III-1877, 4.

Documentos Municipalidad de Valparaíso. Valparaíso, 24-VI-1880. AHN, MV, vol. 52, ff. 476 y ss.

El Mercurio de Valparaíso, ${ }^{\circ} 16324,27-\mathrm{V}-1881,6$.

Documentos Municipalidad de Valparaíso. Valparaiso, 29-V-1881. AHN, MV, vol. 59, ff. 59 y 287.

Documentos Municipalidad de Valparaíso. Valparaíso, 4-III-1886. AHN, MV, vol. 77, f. 14v.

Documentos Municipalidad de Valparaíso. Valparaíso, 4-III-1886. AHN, MV, vol. 77, ff. 35 y ss.

55 Documentos Municipalidad de Valparaíso. Valparaíso, 4-III-1886. AHN, MV, vol. 77, ff. 188-195.
} 
como un bien escaso y por ello en plena discusión respecto a la necesidad de ampliación del suministro, para la cual se planteaba la construcción de un embalse en Peñuelas ${ }^{56}$; los inversionistas Luis Fidel Yáñez, que llegaría a ser promotor fiscal de la ciudad, y Dixon Provand manifestaron su interés de surtir el radio urbano de Valparaíso de agua de mar a domicilio (práctica que el propio Provand implementaría en Iquique desde la Compañía Proveedora de Agua de Iquique ${ }^{57}$, en forma complementaria al servicio municipal, argumentando que así la municipalidad podría ahorrar el $50 \%$ del agua de que disponía, lo que le permitiría extender sus servicios a los cerros, donde se carecía en absoluto o era de muy mala calidad ${ }^{58}$.

Solicitan una concesión por 30 años, planteando que, con el uso del agua del mar propuesto haría inútil llevar a cabo los nuevos planes de obras proyectados en Peñuelas. Su original propuestas pretendía ser un complemento al servicio municipal mediante el que se exigiría al público la utilización del agua de mar para el servicio de desagües y de bomberos (a quienes se proponía abastecer de manera gratuita así como a establecimientos públicos y de beneficencia) ${ }^{59}$. Para 1917, el uso de agua de mar era una realidad en la ciudad y se destinaba a la extinción de incendios, el riego de calles y el lavado de cauces ${ }^{60}$.

Por tanto, el surgimiento de la empresa municipal no significó la desaparición de las empresas privadas de manera radical, pero sí logró el objetivo de evitar que el servicio se convirtiera en un monopolio privado, surgiendo si una nueva preocupación: la posibilidad de que el monopolio ahora fuese municipal.

\section{El debate antimonopolio y la fiscalización del servicio}

Ya hemos visto como en la convocatoria municipal de 1873 solo calificó la Compañía de Consumidores de Agua Potable, la cual había solicitado exclusividad de operaciones y también la participación del Municipio en el financiamiento de las ampliaciones a través de la emisión de bonos, asunto que fue rechazado, argumentando la inconveniencia de hacer negocios con particulares, ya que:

Una larga experiencia ha manifestado que esas compañías han sido siempre desfavorables a los intereses de la ciudad, así es que a nuestro modo de ver, el Cabildo debe o entregar enteramente a la especulación privada un negocio como es el que nos ocupa o tomarlo solo de su cuenta ${ }^{61}$.

El monopolio se veía, así, de manera inevitable y en esas circunstancias el Municipio optaba porque quedara en manos de la iniciativa pública antes que de la privada, alegando que ésta se regía únicamente por un interés mercantil. En contra de una visión netamente comercial, el Municipio abogaba por una economía moral del

\footnotetext{
56 Obra construida durante el gobierno de Federico Errázuriz Echaurren (1895-1900), con el objetivo de ampliar el servicio de agua potable de Valparaíso, especialmente durante los meses de verano.

57 Castro, 2005.

58 Documentos Municipalidad de Valparaíso. Valparaíso, 11-XII-1895. AHN, MV, vol. 144, ff. 153 y ss.

59 Ibídem.

60 El Mercurio de Valparaíso, $\mathrm{n}^{\circ}$ 28027, 05-I-1917, 10.

61 Documentos Municipalidad de Valparaíso. Valparaíso, 4-V-1874. AHN, MV, vol. 33, ff. 415 - 435.
} 
servicio basada en la necesidad de dar cobertura a toda la ciudad y al menor coste, que no podría ser proporcionada por la empresa privada.

Por ello, en 1876, emprende la instalación de una empresa municipal y la puesta en marcha de una estrategia para poner fin a las concesiones dadas a los particulares. Esta consistió en emitir una disposición municipal que ordenaba a todas las empresas retirar las cañerías no autorizadas de las calles, asunto que dio inicio a un conflicto de larga duración entre la Compañía de Consumidores de Agua y el Ayuntamiento que llegó a presentarse ante el Consejo de Estado de $1882^{62}$. La empresa llevó al municipio a los tribunales alegando contra la autoritaria decisión municipal de ordenar levantar "en el término de un mes las cañerías de la Empresa de Consumidores y las demás [...] desde el aviso del Inspector de la policía urbana o el jerente de la Empresa de Agua del Salto"63, argumentando que el municipio no podía ser juez y parte en el pleito establecido entre la empresa y la autoridad edilicia, que no tenía el monopolio que se atribuía para ser el único proveedor de la ciudad y que, según las leyes vigentes, no tenía derecho a negar a la empresa el permiso para tender cañerías, a lo que el intendente Altamirano respondió que era decisión del municipio determinar si el uso de las calles era en beneficio común o no, si no, argumentaba, todo el mundo podría "hacer lo que quisiera en las calles y otras empresas como las de los tranvías o teléfonos no habrían tenido que pedir nunca autorización para instalarse"

La cuestión que preocupaba profundamente a los herederos de Wheelwrigth era que la retirada de algunas de esas cañerías suponía el fin del suministro que daban a los buques. Los argumentos esgrimidos por la Compañía se fundaban en el rechazo a la imposición de un monopolio por parte del Ayuntamiento y también en la previsible incapacidad de la empresa municipal de aguas para cumplir con los requerimientos planteados por el Intendente, en 1872, cuando se fijaron las bases para pedir propuestas de provisión que exigían un mínimo de 9.500 metros cúbicos cada 24 horas, el aumento paulatino en relación al aumento demográfico, el mantenimiento de los precios y el pago de multas en caso de incumplimiento del suministro ${ }^{65}$.

En defensa de la libre competencia afirmaban que:

Lo que Valparaíso quiere y tiene derecho de exigir, es agua en abundancia, barata y que nunca pueda llegar a faltarle, y el único camino para cumplir sus justas exigencias es que haya cinco, diez, veinte empresas, no importa el número, que le cumplan y garanticen esas condiciones ${ }^{66}$.

Junto a ellos, se expresaban otros tantos empresarios en defensa de la libre competencia y en contra de los monopolios y privilegios que sólo podían concederse en contadas ocasiones por parte del Congreso; nunca como una decisión municipal ${ }^{67}$. El Municipio debía intervenir, según ellos, únicamente como regulador y fiscalizador en el caso de incumplimiento de las normas ${ }^{68}$. La competencia era un instrumento

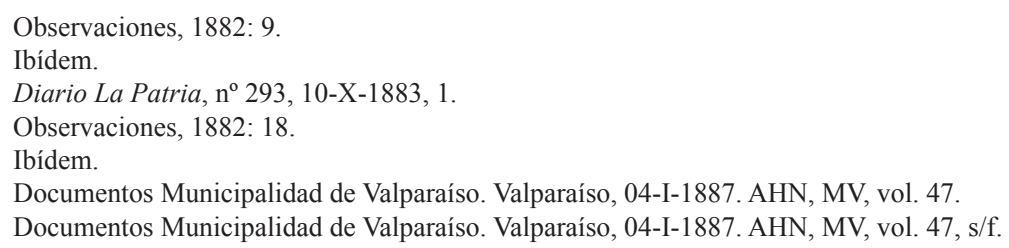


que, aseguraba, según los detractores del monopolio, que no se especulara con los precios, como había demostrado la reciente reducción a 30 centavos por parte de la Compañía de Consumidores de Agua que había obligado a la Empresa Municipal a hacer lo mismo.

A todo esto el Intendente, del lado de la Municipalidad, contraargumentaba, sin embargo, en un alegato completamente a favor del servicio público:

Con textos en la mano se hizo presente en la Municipalidad que en Madrid, Paris, Londres, en importantes ciudades de Alemania y en Nueva York, la provisión de agua comenzó haciéndose por los particulares, y hoy día aquel servicio está en manos de la autoridad: su repartimiento en condiciones ventajosas se estima como una verdadera función pública. Y se comprende fácilmente la razón de este procedimiento.

Si el agua de que un pueblo necesita está en manos de dos o tres empresarios, es mui fácil que lleguen a un acuerdo para fijar un precio relativamente subido. Si, por desgracia, es una la empresa proveedora, la vida del pueblo está en sus manos. Las municipalidades dan necesariamente más garantías. Las censuras de la opinión pública no alcanzan a los particulares y caen pesadas y severas sobre los funcionarios. La prensa no tiene castigos para los particulares que ejercen libremente su industria, pero tiene látigo para flagelar a las autoridades que olvidan que su primer deber es contribuir de todos modos a aumentar el bienestar del pueblo. Una municipalidad no puede recargar el precio del agua sin que su acuerdo sea aprobado por el gobierno; de modo que el abuso no puede perpetrarse sino en el caso de tener malos municipales y peores gobernantes.

Y todavía en esa triste situación hay esperanza.

La vida de las municipalidades es corta, y llegado el momento de la elección el pueblo barrería con la escoba de su indignación a los malos mandatarios que habían especulado con su salad y con su sed. ¿Podría hacer lo mismo con los especuladores privados?

Me parece indudable que las autoridades de las grandes capitales que he nombrado, han procedido con acierto a su cargo la repartición del agua. Cuando este elemento de vida está en poder de la autoridad, está por la misma razón en manos del pueblo, y éste podrá imponer su voluntad. ¿Podrá mandar con la misma autoridad en la especulación privada? ${ }^{69}$.

El debate, lejos de ser una cuestión judicial que se realizara entre municipio y empresa tuvo una gran resonancia en la prensa de Valparaíso. En defensa de la empresa salieron innumerables voces que reprodujeron su alegato a favor de la iniciativa privada en los principales periódicos de la ciudad como respuesta al informe enviado a sus redacciones por el Fiscal, Manuel Montt. Estos periódicos fueron: La Patria, El Mercurio, La Época, El Estandarte Católico y El Independiente. La única voz que salió en defensa del Municipio fue la del Intendente Altamirano ${ }^{70}$.

Durante los años finales del XIX, el principal problema para la empresa pública fue la falta de recursos para aumentar su capacidad. El aumento del consumo la llevó

Vista, 1883: 50.

Vista, 1883. 
en 1893 a proyectar ampliaciones en la captación y acumulación de agua, razón por la cual se acordó contratar un empréstito por 200.000 libras esterlinas (\$2.100.000) para realizar obras de retención en Peñuelas, colocando en garantía las instalaciones de la Empresa de Agua Potable del Salto ${ }^{71}$, el que fue cursado por la Casa Henry Schoereder y Cía. de Londres. De una manera u otra, el abastecimiento de agua siguió dependiendo de la iniciativa privada.

La proyección económica de la inversión parecía óptima, ya que se estimaba que las obras serían una fuente positiva de ingresos para el Municipio, permitiéndolo hacer con holgura el servicio de la deuda y quedar un saldo para atender otras necesidades, calculado sobre la base de vender 20.000 metros cúbicos al día a 0.25 centavos, lo que implicaría la disponibilidad de igual cantidad que se podría destinar al riego de calles, limpia de cauces y riego de algunas colinas que rodean al puerto ${ }^{72}$. Sin embargo la Municipalidad no estaba en condiciones, seguramente por la crisis económica por la que atravesaba el país; de avalar el préstamo, por lo que solicitó el concurso del Estado sea para hacerse cargo de los trabajos necesarios o garantirla ante los organismos financieros ${ }^{73}$, argumentando que se aprovecharían parte de esas aguas para el riego, lo que implicaría una nueva fuente de ingresos. Sin el apoyo del Estado, las obras deberían paralizarse, lo que significaría la muerte del proyecto y la perdida de sobre un millón de pesos ya invertidos ${ }^{74}$.

En mayo de 1897 el apoyo del Estado era una realidad, ya que un informe daba cuenta de los avances de las obras de construcción del tranque que tendría una capacidad de 260.000 metros cúbicos ${ }^{75}$. Poco después, en enero del año siguiente se sancionó el traspaso de la empresa municipal al estado, estableciéndose que el destino de los recursos que produjera la empresa y las utilidades reportadas por la cesión de aguas a particulares, serían percibidas por el fisco, pero abonadas a la cuenta de la I. Municipalidad. Así, en 1901 el asunto de la administración del agua potable estaba en una situación confusa, coexistiendo en la práctica dos poderes: la Municipalidad y el Estado, lo cual dificultaba aún más su recuperación y el pago total del empréstito ${ }^{76}$ $\mathrm{y}$, finalmente, terminó siendo totalmente intervenida por el gobierno central en 1917, con la decisión estatal de:

adquirir de la Municipalidad de Valparaíso los derechos que ésta conserva sobre la Empresa de Agua Potable de ese puerto, por la suma de un millón novecientos setenta i dos mil ochocientos cuarenta i dos pesos ocho centavos $(\$ 1.962,842.08)$ que se reconoce a la Municipalidad en los balances de la Empresa ${ }^{77}$.

Así se cumple para Valparaíso, el esquema del traspaso de gestión de las empresas municipales que se repitió en otras ciudades europeas y americanas en las que en el largo proceso de modernización del sistema de abastecimiento de agua, se vivió un

\footnotetext{
Documentos Municipalidad de Valparaíso. Valparaíso, 02-III-1893. AHN, MV, vol. 180, s/f.

Documentos Municipalidad de Valparaíso. Valparaíso, 06-VII-1897. AHN, IV, vol. 853.

Ibídem.

Ibídem.

Documentos Municipalidad de Valparaíso. Valparaíso, 28-0V-1897. AHN, MV, vol. 138.

Documentos Municipalidad de Valparaíso. Valparaíso, 05-VII-1901. AHN, MV, vol. 174, f. 458.

Ministerio del Interior, Ley 3.213. Santiago, 16-II-1917. Disponible en https://www.leychile.cl/ Navegar?idNorma=23816.
} 
primer momento de predominio de la iniciativa privada entre 1800 y 1880 , seguido de un período en el que convivieron la iniciativa privada con la pública, entre 1880 y 1930, mientras que, a partir de los años 30 se vivió el auge de la municipalización de las empresas privadas quedando el "monopolio natural" en manos de las instituciones locales o estatales ${ }^{78}$.

\section{Conclusiones}

Las directrices del higienismo fueron calando muy lentamente y su puesta en práctica, que al principio se consideraba un lujo, se fue reconociendo, poco a poco, como una necesidad ineludible. Los portavoces del nuevo paradigma fueron una serie de profesionales entre los que se encontraban médicos e ingenieros sanitarios, pero también las propias autoridades a las que, lentamente, se les fue haciendo responsables del cuidado de la higiene y la distribución de las aguas, si no como proveedoras sí, al menos, como fiscalizadoras del buen uso. Como decimos, el proceso fue lento, al igual que ocurrió en otras ciudades americanas y europeas. Como señala Matés, hubo una serie de factores que incidieron en que la "revolución" en el modelo de abastecimiento durara décadas, pero también hubo una serie de circunstancias, como fueron los cambios producidos en materia de salud e higiene a nivel nacional e internacional que obligaron a las pujantes ciudades y puertos a la modernización bajo el imperativo de los intercambios comerciales y de personas. "A finales del Antiguo Régimen, disponer de agua potable en la propia casa era algo bastante inimaginable, pero progresivamente se fue haciendo realidad en el seno de una civilización urbana e industrial"79. En aras de la modernización, el agua se convirtió en un potencial negocio. Lo que dio sus primeros pasos como iniciativa privada, se terminó imponiendo como una obligación que debían cumplir las nuevas ciudades que querían no ser excluidas de los circuitos internacionales comerciales. Las exclusiones supusieron, entonces, motivo de cuestionamiento de las capacidades de los gobiernos locales. Por ello el abastecimiento pasó de ser obligación local a incluirse entre los imperativos de los gobiernos centrales. Ello implicó también que se diera inicio a la discusión en torno a la propiedad de las empresas de agua y a que se comenzara a cuestionar que quedaran en manos de los intereses privados, como había ocurrido en los inicios del proceso de modernización.

La transformación del modelo significó la remodelación de las ciudades de acuerdo al nuevo paradigma que exigía ordenar el espacio y controlar las aguas siguiendo el modelo positivista de "orden y progreso" llevado a la práctica por higienistas e ingenieros hidráulicos ${ }^{80}$. En Valparaíso, dicho control supuso la erradicación de muchas enfermedades y de las epidemias que periódicamente asolaban el puerto, pero también implicó dar la espalda a las condiciones naturales de los cursos de agua y de la climatología. El almacenamiento y la desviación de cursos de agua posibilitó la dotación de agua a una población en continuo crecimiento, pero todo ello se realizó de forma insostenible. Siguiendo las pautas del desarrollo y el crecimiento a toda costa, se ganó terreno al mar, a los cerros, a las quebradas. Con estas medidas, el

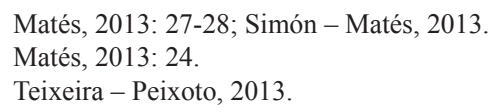


agua quedó soterrada pero no por ello desapareció y las continuas inundaciones que se sucedieron a lo largo del XIX y el XX son prueba de ello ${ }^{81}$.

Como hemos visto, en principio, el Municipio no contó con suficiente capital para emprender el proceso ni con la capacidad de presión suficiente como para modificar el débil sistema impositivo. El precio político de aumentar los impuestos era muy elevado y la iniciativa privada se encontraba perfectamente articulada como para ofrecer resistencia a cualquier intento por revertir el orden de cosas. El empresariado local se encontraba coludido con la prensa, como se vio en el cierre de filas que se produjo en torno al esfuerzo del Municipio por frenar el avance de la Compañía de Consumidores de Agua. Por ello se vio forzada la empresa municipal a intentar obtener financiación mediante suscripción pública en lo que se presentó en la prensa como un esfuerzo patriótico por eludir la concentración del servicio en manos privadas. También se hizo necesario recurrir a empréstitos, que encarecieron y ralentizaron las obras.

Las inversiones privadas estuvieron destinadas desde un principio a mejorar las condiciones de acceso al agua por parte de las navieras o de las haciendas. También hemos mencionado en estas páginas el caso del Canal de las Mercedes, al reseñar las propuestas que fueron rechazadas en el concurso emitido por la Intendencia de Valparaíso. El intento frustrado de implicar al municipio en la financiación del mismo, por parte de Stephan, Drouilly o Gubler no es más que una manifestación de las prioridades que las elites comerciales, y de los negocios (con apoyo de ingenieros y aventureros, como el topógrafo Drouilly, que formó parte del proceso de colonización de Valdivia y Llanquihue), daban a los usos del agua y a la inversión de sus capitales $^{82}$. El Canal de Las Mercedes, en el que estuvieron vinculados presidentes de la República, como Manuel Montt y Balmaceda, no es más que la demostración de la colusión entre los intereses privados y públicos. Durante cerca de treinta años se emprendieron grandes obras destinadas a transportar agua desde el Río Mapocho a Valparaíso. Finalmente, estas aguas sólo llegaron a Curacaví, a las haciendas de Javier Bustamante, después de pasar por las de los otros miembros que conformaron la Sociedad del Canal de Las Mercedes ${ }^{83}$, de la misma manera que ocurrió con los casos aquí estudiados del Canal de Quillota -que terminó beneficiando únicamente a las propiedades agrícolas de Waddigton- o con las cañerías instaladas por el empresario aventurero, William Wheelwrigth, -que abasteció con ellas a los buques de su compañía naviera en su tránsito por el Puerto.

Las grandes obras se sustentaron con capitales británicos y estadounidenses y se construyeron con materiales procedentes de empresas extranjeras a muy elevados cotos para la población de Valparaíso que se encontró, permanentemente, merced de los intereses de la iniciativa privada a pesar de los intentos realizados por el Municipio y la Intendencia entre 1876 y 1917. Al finalizar el período, la intervención del gobierno central, ocurrida cuando se hizo evidente la incapacidad del Municipio para

81 Álvarez, 2001.

82 Esta colusión de intereses confluye en lo que Topalov define como "nebulosa reformista". Se conforma como un grupo de empresarios e intelectuales formó parte de una «nebulosa reformista» compuesta por médicos, funcionarios públicos, ingenieros sanitarios, contratistas, etc. implicados en una idea y un interés común: transformar las condiciones higiénico sanitarias de las ciudades para modificar, a su vez, la vida de sus ciudadanos en aras de la modernización y la agilidad en las relaciones de intercambio de bienes y personas en el mercado global. Topalov, 2004

83 Correa, 1973. 
hacer frente a los intereses de la deuda, dejo a los porteños sin capacidad de decisión en torno a la gestión del servicio de agua en la ciudad.

\section{Referencias bibliográficas}

Álvarez, Luis. "Origen de los espacios públicos en Valparaíso: el discurso higienista y las condiciones ambientales en el siglo XIX". Revista de Urbanismo, $\mathrm{n}^{\circ} 4$, (2001). Disponible en http://web.uchile.cl/vignette/revistaurbanismo/n4/alvarez/alvarez.html

Birrichaga, Diana. "Las empresas de agua potable en México (1887-1930)". En Historia de los usos de agua en México. Oligarquías, empresas y ayuntamientos (1840-1940), coordinado por Suárez Cortez, Blanca Estela. México: Comisión Nacional de Agua CIESAS - IMTA, 1998, 181-225.

- La modernización del sistema de agua potable en México, 1810-1950. Toluca: Colegio Mexiquense, 2007.

Calderón, Alfonso - Schlotfeldt, Marilis. Memorial de Valparaíso. Santiago: Editorial Ril, 2001.

Castro, Luis. "Historia del aprovisionamiento de agua potable en el puerto de Iquique". Archivo Histórico del Agua, n 30 (2005), 30-37.

- Modernización y conflicto social: la expropiación de las aguas de regadio a los campesinos del Valle de Quisma y el abastecimiento fiscal de Iquique, 1880-1937. Valparaíso: Editorial de la Universidad de Valparaíso, 2010.

Cavieres, Eduardo. "Valparaíso en la segunda mitad del siglo XIX. Historia Urbana y aproximaciones demográficas". En Historias Urbanas. Homenaje a Armando de Ramón, editado por Valenzuela, Jaime. Santiago: Instituto de Historia - Universidad Católica de Chile, 2007, 123-141.

Correa Saavedra, Mario. "Agua y cauce de Las Mercedes". En Homenaje Guillermo Feliú Cruz, editado por Blanc, Neville. Santiago: Editorial Andrés Bello, 1973, 137-150.

Díaz, Wenceslao. Memoria de la Comisión Directiva del Servicio Sanitario del Cólera presentada al Señor Ministro del Interior. Santiago: Imprenta Nacional, 1888.

Flores, Sergio. "Memoria e imaginario de Valparaíso: 1860-1940". En Historias Urbanas. Homenaje a Armando de Ramón, editado por Valenzuela, Jaime. Santiago: Instituto de Historia - Universidad Católica de Chile, 2007, 141-160.

Goubert, Jean Pierre. The conquest of Water. The advent of health in the industrial age. Princeton: Princeton University, 1989.

Mannheim, J.B. Estudio crítico sobre la evacuación jeneral de la ciudad de Valparaíso. Memoria presentada en 1875 al señor Intendente Echaurren. Valparaíso: Imprenta del Deber, 1876.

Matés, Juan Manuel. La conquista del agua. Historia económica del abastecimiento urbano. Jaén: Universidad de Jaén, 1999.

- La conquista del agua en Europa: los modelos de gestión (siglos XIX y XX). Agua y Territorio, $\mathrm{n}^{\mathrm{o}} 1$, enero-junio (2013), 21-30.

Melosi, Martin. The Sanitary City: Urban Infraestructure en America from Colonial Times to the Present (Creating the Latin American Landscape). Baltimore: The Johns Hopkins University Press, 1999.

Molina Ahumada, Mauricio. "Historia, salud y enfermedad. La noción de salud e higiene pública. El caso de la dotación de agua potable en Valparaíso, 1850-1910. Reconstrucción 
de sus significados". Revista Archivum (Archivo Viña del Mar), año VIII, no 9 (2009), 203-221. Disponible en https://archivohp.files.wordpress.com/2008/08/molina.pdf

Nazer Ahumada, Ricardo. "La fortuna de Agustín Edwards Ossandon: 1815-1878”. Historia, vol. 33 (2000), 369-415.

Ortega, Luís. Chile en ruta al capitalismo. Cambio, euforia y depresión, 1850-1880. Santiago: DIBAM/LOM, 2005.

Observaciones al informe de la Ilustre Municipalidad de Valparaíso presentadas al Exmo. Consejo de Estado. Valparaíso: Imprenta de la patria, 1882.

Sánchez Andaur, Raúl - Simón Ruiz, Inmaculada. "Cambio de paradigma y primera empresa de agua en la ciudad de Talca (1860-1930)". Tiempo Histórico, n 9 (2014), 89-107.

Simón Ruiz, Inmaculada - Matés, Juan Manuel. "El abastecimiento de agua potable en México y España: cambio institucional y aparición de las empresas privadas (18701930)". En Agua, territorio y medio ambiente. Políticas públicas y participación ciudadana, editado por Navarro, Jesús Raúl - Regalado, Jorge - Tortolero, Alejandro. Guadalajara: Seminario Permanente ATMA - CSIC, 2013, 21-49.

The Pacific Steam Navigation. Noventa años en Chile. El relato del establecimiento de la navegación por vapor en el Pacifico. Valparaíso, 1930.

Teixeira y Peixoto, Teresa de. "Saber Científico e poder instituído como campo de disputas no processo de instalação e gestão da água em Campos dos Goytacazes: o legado da Companhia The Campos Syndicate Limited”. En Agua y Territorio, n 1 (2013), 65-76.

Topalov, Christian. "De la cuestión social a los problemas urbanos: los reformadores y la población de las metrópolis a principios del siglo XX". En Política social y economía del trabajo, compilado por Danani, Claudia. Buenos Aires: UNGS - OSDE -Altamira, 2004, 47-71.

Urbina Burgos, Rodolfo. Auge y ocaso del viejo "Pancho" 1830-1930. Valparaíso: Ediciones Universidad de Playa Ancha, 1999.

Urbina Carrasco, María Ximena. Los conventillos de Valparaíso, 1880-1920. Fisonomía y percepción de una vivienda popular urbana. Valparaíso: Ediciones Universitarias de Valparaíso - Pontificia Universidad Católica de Valparaíso, 2012.

Vela-Ruiz, Alonso. "Iniciativas para abastecer de agua a Valparaíso. 1847-1901". Revista Archivum (Archivo Viña del Mar), año V, no 6 (2014), 214-226. Disponible en https:// docs.google.com/file/d/0B2bp8ygFxx8QdFVNcjloNXUwVzg/edit

Vicuña Mackenna, B. De Valparaíso a Santiago, tomo II. Santiago: Chile, Imprenta de la Librería del Mercurio, 1877.

Vista del Fiscal, señor Don Ambrosio Montt, presentada al Consejo de Estado con motivo de la reclamación interpuesta por la Compañía de Consumidores de Agua contra el acuerdo municipal que se atribuye el dominio de las calles y de las plazas públicas. Santiago: Imprenta La Patria, 1883. 